\title{
FIBER-OPTIC SENSOR FOR MONITORING SYNCHRONICITY OF ACTUATORS
}

\author{
GUDKOV, Y.
}

Abstract: In most projects aimed at modernization of existing production lines and units a new group of mechatronic objects - interconnected multi-motor electric drives - is used. For the efficient and safe operation of this type of drives it is necessary to solve a number of problems, one of which is the development of methods and tools to synchronize the rotation of activators dynamically. The purpose of the research is to create a non-contact sensor for measuring the rotation of the activator. The basis of the developed sensor is a fiber optic converter with external modulation, with which you can implement a non-contact method of measuring displacement of reflective label installed on the shaft of remote devices. To compensate the non-informative factors affecting the accuracy of the position measurement, the original block diagram and processing algorithm were developed which provides stable and accurate registration of appearing the reflective labels under the fiber end when using the sensor in a production environment. The results of the research have made a theoretical basis for the design of the two measuring devices: a high-speed tachometer and a sensor for control of synchronicity rotation in the dynamic mode.

Key words: optical fiber, non-contact sensor, synchronicity, actuator, reflective label
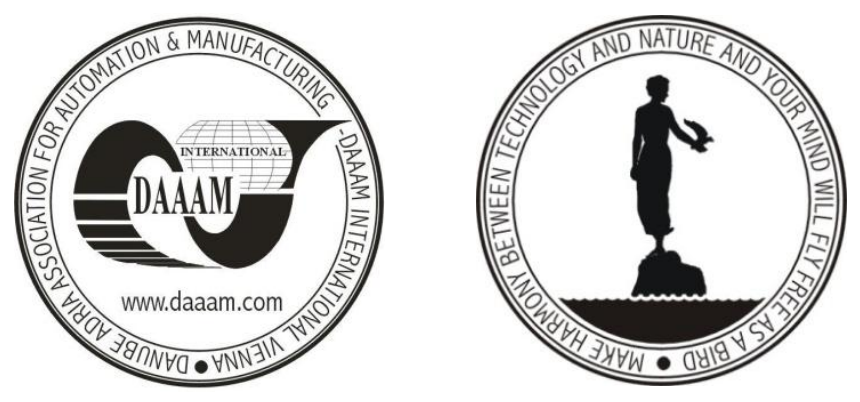

Authors' data: Gudkov, Y[ury], National Research University Higher School of Economics, 20 Myasnitskaya Ulitsa, Moscow 101000, Russia, ygudkov@ @se.ru

This Publication has to be referred as: Gudkov, Y[ury] (2014). Fiber-Optic Sensor for Monitoring Synchronicity of Actuators, Chapter 48 in DAAAM International Scientific Book 2014, pp.597-604, B. Katalinic (Ed.), Published by DAAAM International, ISBN 978-3-901509-98-8, ISSN 1726-9687, Vienna, Austria DOI:10.2507/daaam.scibook.2014.48 


\section{Introduction}

One of the challenges that must be addressed to developers of machines and mechanisms is to provide synchronicity rotation of the individual actuator. If a synchronicity rotation simply means constancy of the speed of rotation, the synchronization system can be built based on the tachometers, widely available on the market.

However, for precision technological equipment and mobile robots urgent task is to control not only the speed of rotation, but the error of relative angles of rotation of the actuator during operation due to accidental slip or jam. In fact, this type of synchronization system must dynamically control the rotational phase of the actuator, defined during the initial installation.

Similar problems arise in the modernization of production lines and units. In most cases, these projects are based on the use of multi-motor electric drives, which belong to a new group of mechatronic objects. For safe and efficient use of such drives it is necessary to solve a number of problems, one of which is the development of methods and tools to synchronize the rotation of actuators in a dynamic mode (Breido, 2013).

No less complicated is the rotation parameters and control of $\mathrm{AC}$ induction motors. In some cases, for the correct operation of the engine sensors of velocity are impossible to use because of their influence on the magnetic flux in the motor control (Vaclavek \& Blaha, 2007).

Thus, the urgent task is to create a sensor for monitoring actuators, which must meet the following requirements:

- Wide frequency range.

- Minimal impact of the sensor on the performance of the sensor actuator.

- Minimal impact of electromagnetic fields of the actuator on the electronic components of the sensor.

Fiber-optic sensors are fully responsible for the latter requirement, they are well known in the control and diagnostic equipment market (Okosi et al., 1991).

The analysis of existing technical solutions of fiber-optic sensors showed that by the method of obtaining the measuring information they can be classified as follows:

- Converters based on phase modulation of the radiation flux.

- Converters based on spectral analysis of the reflected radiation flux.

- Converters based on the Doppler's effect.

- Converters with modulation of the radiation flux intensity.

Converters with phase modulation of the radiation flux have a very high accuracy and are based on the effects of interference and diffraction of coherent radiation emitted by the laser. Sagnac interference gyroscopes are best known, as well as fiber-optic converters of mechanical vibrations on the basis of Bragg gratings with an accuracy of approximately 0.01 microns. 
In converters using spectral analysis an object of measurements is irradiated by the flux with a wide range of radiation. Under the influence of the value being measured individual sections of the radiation spectrum are absorbed by the object that is fixed by the receiver. Such converters are used for example in analyzing the composition of petroleum products etc.

Converters based on the Doppler's effect are used mainly in the optical location and astrophysical measurements. Thanks to the small divergence of the laser beam very high precision of measurement of angular purpose coordinates is provided.

All of the above fiber-optic sensors deliver high accuracy, but are too expensive for use in the control systems of technological equipment and are mainly used in measuring laboratories (Garmash et al., 2005).

The most appropriate option of fiber-optic sensors for use in such systems can be considered converters based on the amplitude modulation of the radiation flux (Murashkina \& Volchikhin, 1999), which, along with potentially high precision and wide frequency range have low cost. One of the options of the amplitude sensors are fiber optic sensors with external modulation (Zak, 1989).

\section{Ordinary fiber-optic sensor with external modulation}

The main advantages of such a fiber-optic sensor with external modulation is a non-contact method of obtaining measurement information, the frequency range from zero hertz to hundreds of kilohertz, the lack of effect of electromagnetic interference on the sensing element, high reliability capacity, durability, small size and weight, compatibility with microelectronic components (Gudkov \& Tuv, 2013).

Generalized structure of the simplest fiber-optic sensor with external modulation (Fig.1.a) includes a multicore fiber with one transmitting and one receiving channels, a light source and a photodetector. The flow of the light source via the transmitting optical fiber reaches the surface of the test object and the reflected flow through the receiving optical fiber returns to the photodetector. The output signal of the photodetector depends upon the design and dimensions of the optical fibers, the direction of movement of the object, the reflection properties of its surface, the gap between the object and the common end of fibers and absorbing medium in this gap. Typically, in such a structure a light source is an infrared LED and a photodetector - a silicon photodiode, which provides maximum spectral matching of the sensor components.

Two types of the measuring circuit can be implemented on the basis of the structure. One is to control axial movements of the object, and the other - for the control of orthogonal movements relative to the total fiber end (Zak, 1989). To construct the sensor of rotation speed of the actuator can be successfully applied the measuring circuit monitoring orthogonal displacement of the object, the role of which is played by the reflective label fixed on the actuator. Conversion function of the sensor in such a measuring circuit is shown in Fig.1.b. 


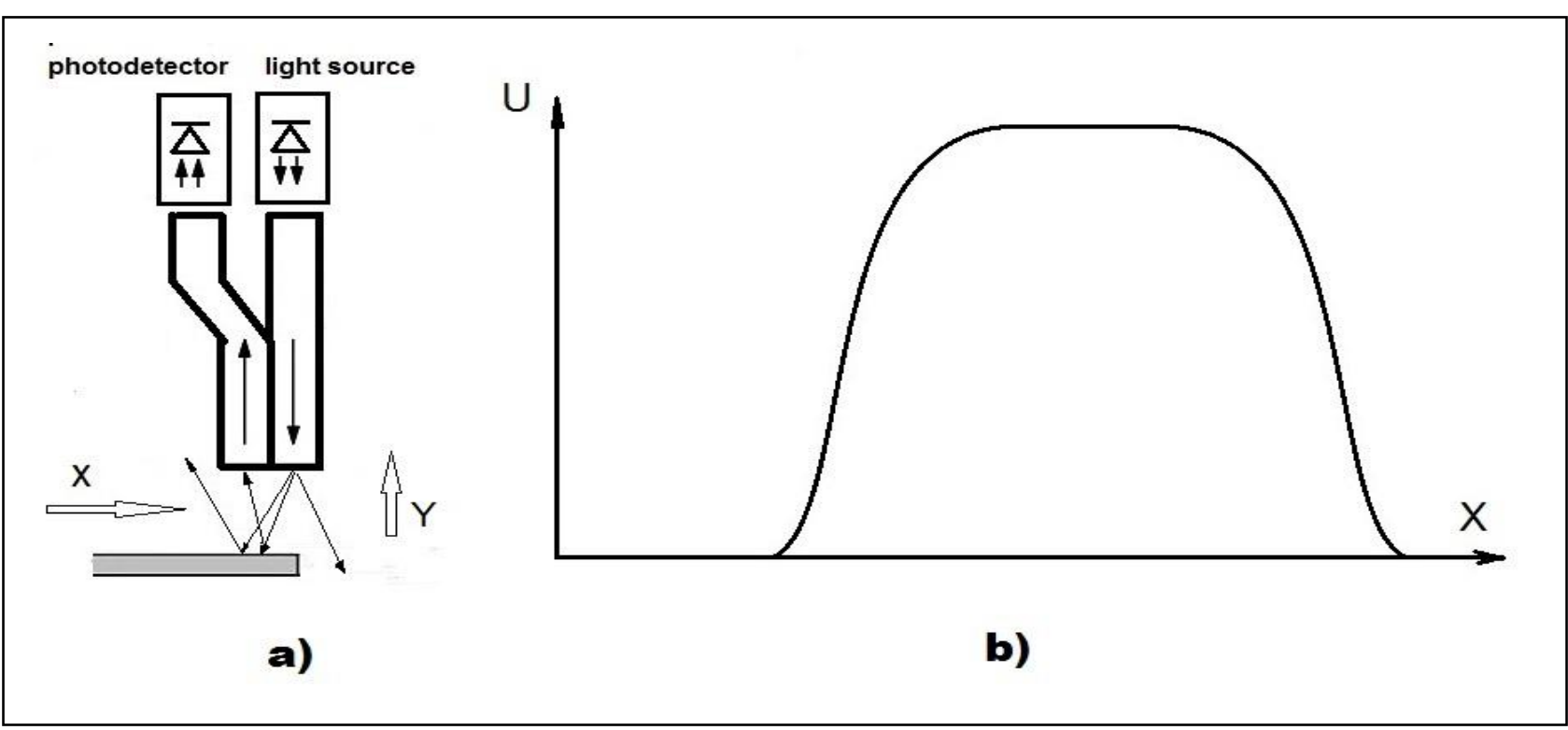

Fig. 1. Structure and function of the transmission sensor with external modulation

A simple embodiment of a measuring device of the velocity of rotation of the actuator may comprise a comparator for generating pulses when passing the label under the sensor and the timer for measuring time intervals between edges of pulses. In turn, to control the angle of rotation of the actuators with respect to each other in dynamic it is enough to measure time intervals between the instants of passage of labels fixed on different actuators.

However, a significant drawback of the fiber-optic sensor with external modulation is a strong dependence of the accuracy of the measurement of the object movements from external uninformative factors, the main ones are:

- Drift of the flow intensity of light source associated with its degradation, changes in ambient temperature and power supply ripple.

- Change of the reflection properties of the surface of the controlled object and optical losses in the gap caused by dust, powders, etc.

This leads to the fact that the fiber-optic sensor with such a structure is usually only applicable in laboratory conditions, as it requires calibration before each measurement cycle.

\section{Principle of operation of the sensor}

The developed block diagram of the fiber-optic sensor for registering the moment of the reflective label passage (Fig.2) allows virtually to eliminate the impact of the above factors and to ensure long-term stability and the absence of false actuations in real-world conditions.

The main difference of the block diagram is the use of two receiving optical fibers disposed symmetrically with respect to a transmitting optical fiber and the processing circuit of the measuring information, which includes two photodetectors (PH1, $\mathrm{PH} 2)$, three comparators $(\mathrm{C} 1, \mathrm{C} 2$ and $\mathrm{C} 3)$, two dividers of signals (D1 and D2), 
a fixed voltage reference (FVR), a pulse generator (PG) and analog-to-digital converter (ADC).

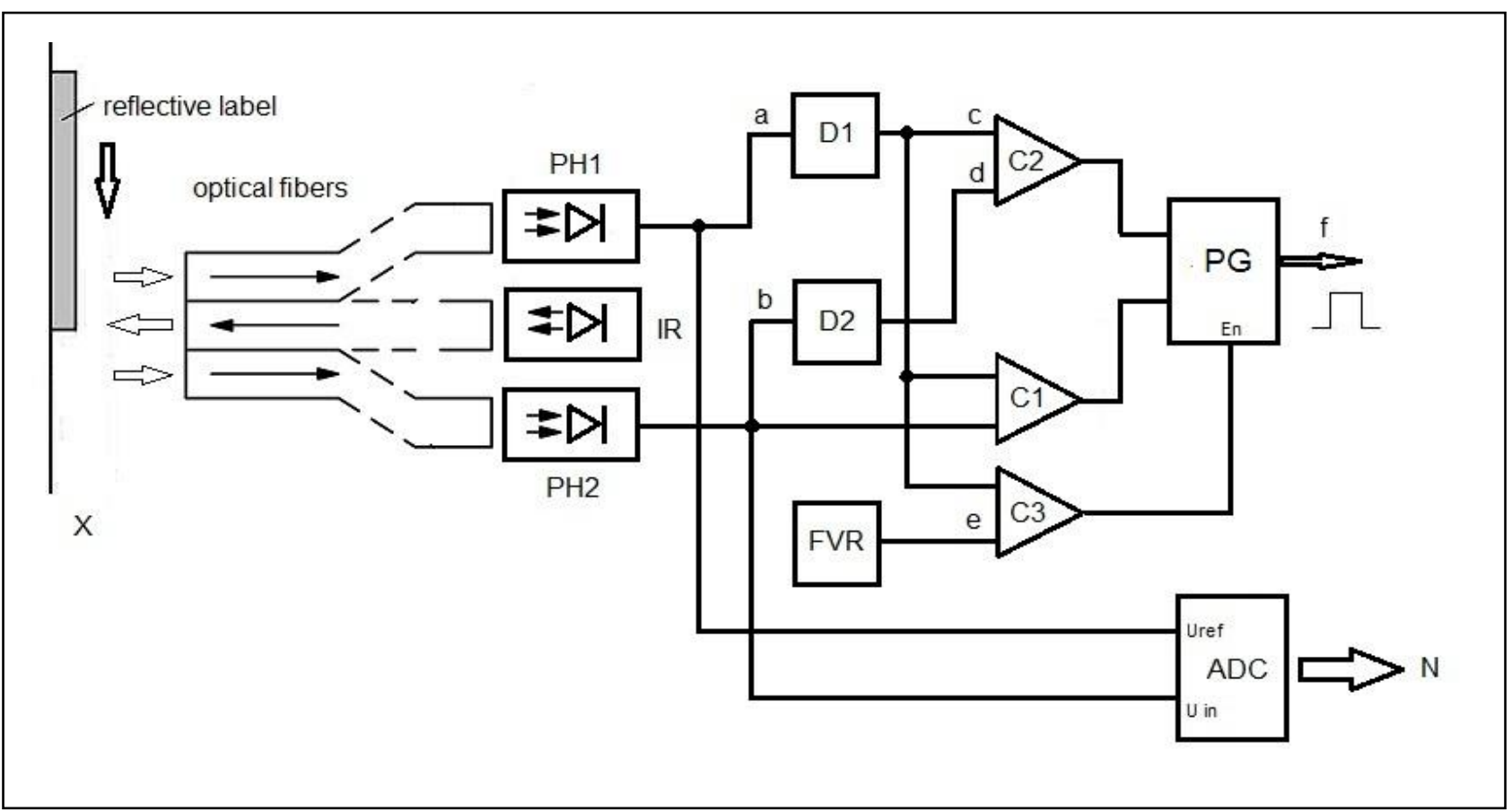

Fig. 2. Block diagram of the sensor

The algorithm of the sensor shows a timing diagram of signals of the processing circuit by passing reflective label under the fibers (Fig.3).

Suppose that in the initial state the reflective label is out of the total fibers end and the signals on the photodetectors are close to zero. Moving a label in the $\mathrm{X}$ direction generates a signal appearance of the photodetector PH1 (signal a), the instantaneous value of which depends on the position of the label end relative to the boundaries of the fibers end, the flow of the light source and the impact of factors affecting its propagation and reflection. With further movement of the reflective label the signal similar to the form appears on the photodetector PH2 (signal b). Moreover, this signal continues to grow while the signal of the photodetector PH1 has reached its maximum. In point $\mathrm{x} 1$ dependence of the signal of the photodetector $\mathrm{PH} 2$ from movement of the reflective label is maximum, and the signal of the photodetector PH1 is independent of its movement. Moreover, the value of both signals is equally dependent on the light flow and its propagation and reflection losses.

Signals of the divider D1 (signal c) and photodetector PH2 coming to the comparator $\mathrm{C} 1$ lead to its triggering in point $\mathrm{x} 1$. The moment of trigger depends only on the position of the label edge. The signal of the comparator $\mathrm{C} 1$ is supplied to one of the inputs of the pulse generator PG. However, the signal of the logic "1" at its output is only set when there is an active signal from the comparator $\mathrm{C} 3$, which is triggered if the value of the signal at the output of the divider D1 is greater than the signal (signal e) of the fixed voltage reference FVR. The FVR level actually determines the noise immunity of the sensor and is given based on the evaluation of the degree of influence of non-informative factors on the amplitude of the signals of photodetectors and the flow of ambient light. 


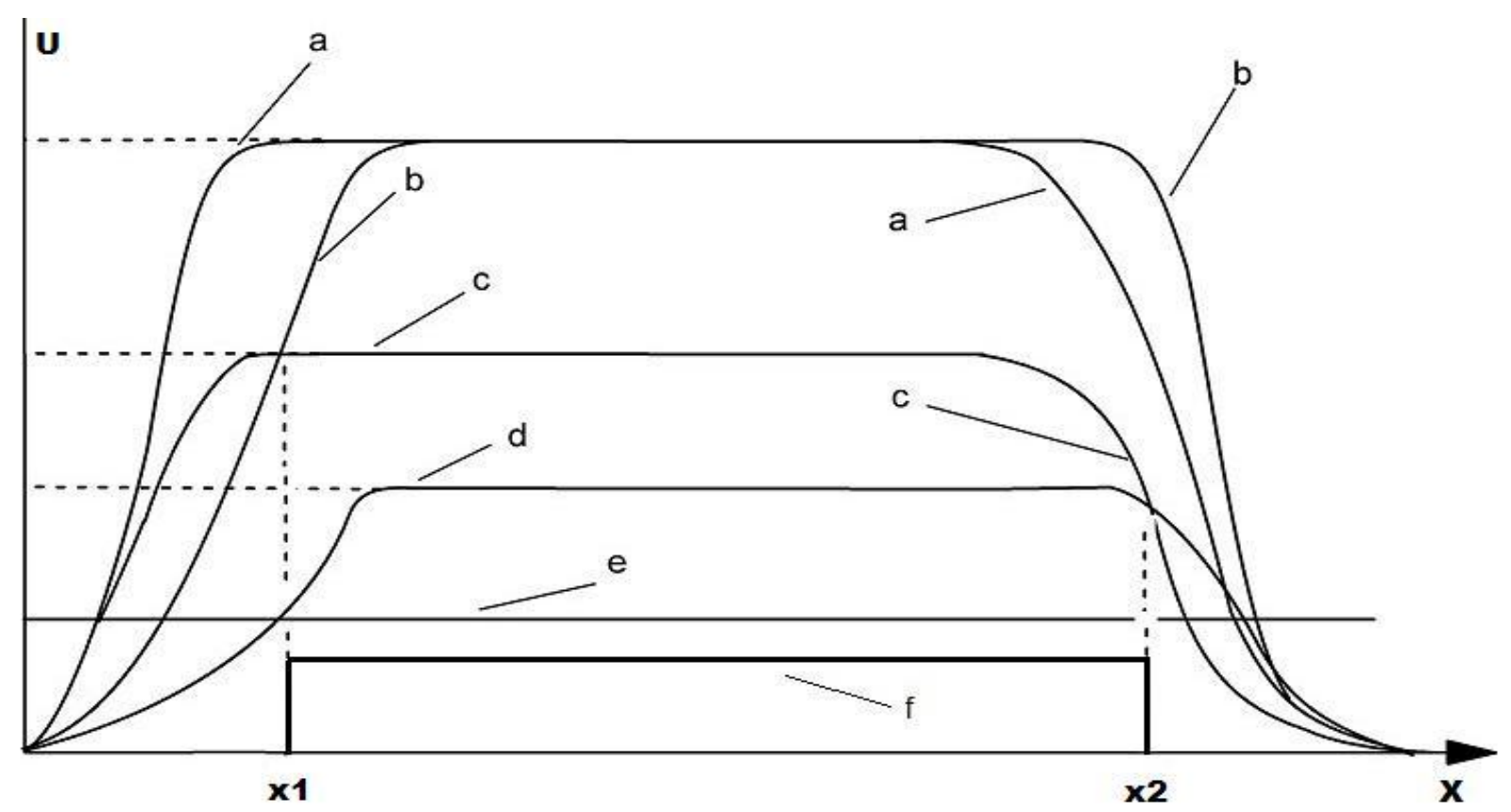

Fig. 3. Timing diagram of the sensor signals

To reset the pulse generator PG to a logical " 0 " is a divider D2 and a comparator C2. This circuit also prevents false triggering of the pulse forming circuit when driving in the opposite direction. When reverse rotation the edge of the reflective label first enters the field of view of the photodetector PH2. Therefore, the signal of the photodetector $\mathrm{PH} 2$ reaches a maximum value before the signal of the photodetector $\mathrm{PH} 1$. At the point $\mathrm{x} 2$ the triggering of the comparator $\mathrm{C} 2$ occurs, the active signal of which blocks the pulse generator PG which doesn't turn to a logical "1" by passing a point $\mathrm{x} 1$ by the reflective label.

At slow rotation of the actuator the output code of the analog-to-digital converter ADC allows us to estimate the current position of the label edge relative to the point $\mathrm{x} 1$, which makes it possible to use the sensor in positioning devices. Since the ADC actually performs digital division of photodetector signals, which are equally dependent on the light flow and losses on its distribution, its output code depends only on the movement of the reflective label relative to the total end of the fibers.

\section{Practical implementation}

The proposed block diagram and the algorithm of the sensor formed the basis for the development of two devices: a measuring device of the speed of rotation and a sensor for monitoring synchronicity rotation of the actuator.

In the measuring device of the speed of rotation the whole circuit of measurement information processing can be successfully built based on a microcontroller the architecture of which includes resident timers, and resources for 
analog signal processing. Depending on the mode setting of the timer the device can perform two functions:

- "Classic" tachometer. The timer counts the pulses generated by the passage of the reflective label.

- Fast measuring device of the "instantaneous" rotation speed. The timer counts the duration of time intervals between the edges of the pulses generated by passing the reflective label. In this case, the calculated value of the rotation speed is updated after each turnover of the actuator.

In practice of the sensor for monitoring the synchronicity rotation of the actuator the use of a microcontroller in a processing circuit of the measuring information of the sensor is unnecessarily. Using commercially available precision comparators in the device will provide high precision of registration of the reflective label edges, and the pulse generator, built on the basis of two standard D-triggers, produces a minimum delay in the formation of the output pulse of the device.

The results obtained provide a practical basis for the development of multichannel systems of monitoring the synchronicity rotation of the actuator in the technological equipment and industrial robots.

A block diagram of the control system of synchronicity rotation of actuators in dynamic mode is presented in Fig.4.

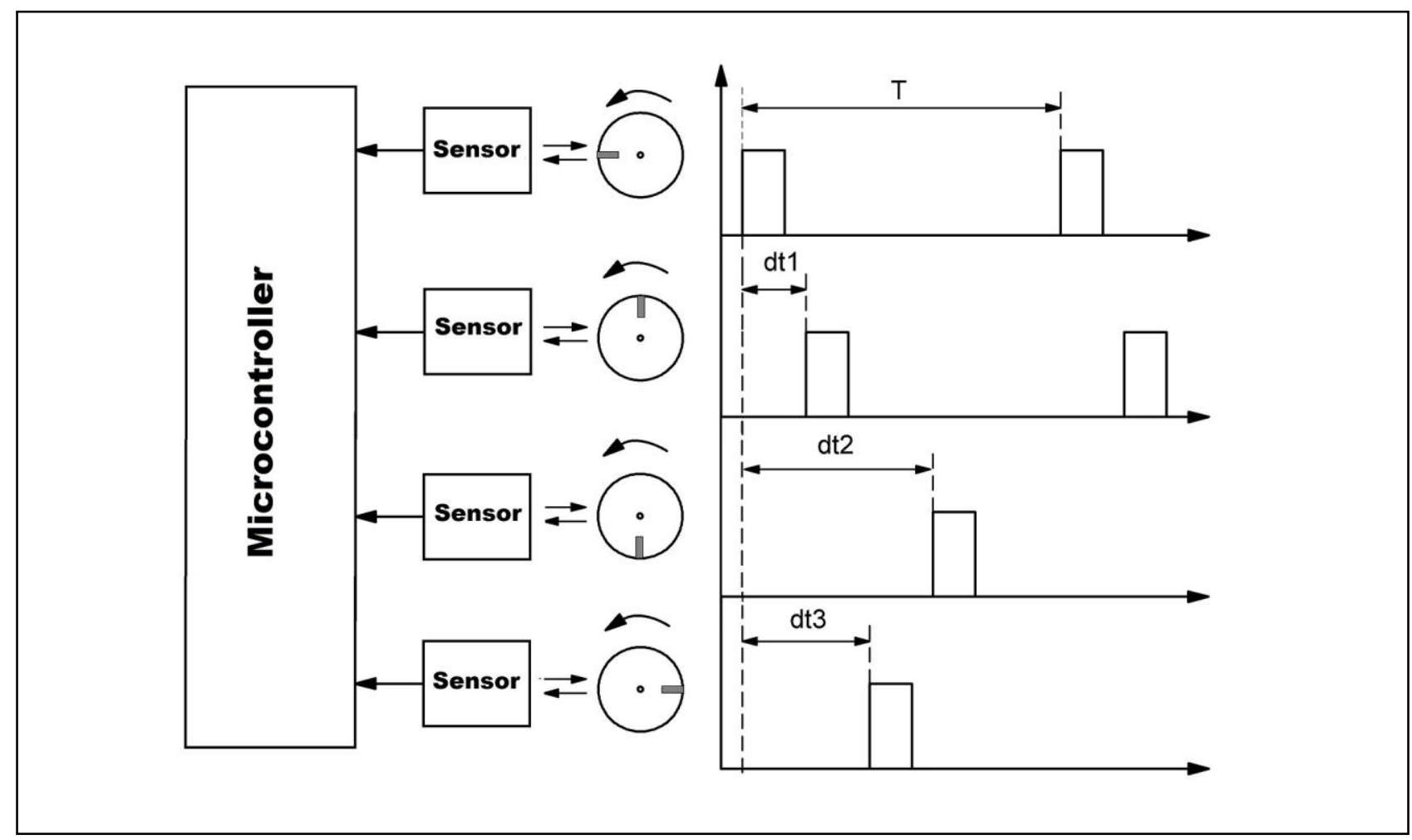

Fig. 4. Block diagram of the control system of synchronicity rotation

The algorithm of the system provides for continuous measurement of time intervals dTi between the fronts of rise generated by sensors, after the working mode of actuators. To reduce the influence of the rotational speed on the accuracy of the 
control error signals of synchronicity are generated by the microcontroller when changing relationship dTi / T.

Experimental studies of the measurement accuracy of positioning boundaries of reflective label were made for the sensor having one transmitting and two receiving fibers with square ends size $5 \times 10 \mathrm{~mm}$. It has been established that such a length of the linear portion of the transfer function $\mathrm{U}=\mathrm{F}(\mathrm{x})$ of this sensor is approximately $8 \mathrm{~mm}$ and the sensitivity to the label movement $-1 \mathrm{~V} / \mathrm{mm}$.

This makes it possible to use the sensor, not only for the control of synchronicity rotation of actuators, but also for non-contact measurement of linear displacement of pneumatic proportional valves with piezoelectric actuator the positioning accuracy of which according to the authors (Avram et al., 2011) can reach $0.3 \mathrm{~mm}$.

\section{References}

Avram, M.; Bucsan, C.; Duminica, D.; Bogatu, L. \& Spanu, A.R. (2011). Pneumatic Proportional Valve with Piezoelectric Actuator, Chapter 27 in DAAAM International Scientific Book 2011, pp. 331-346, B. Katalinic (Ed.), Published by DAAAM International, ISBN 978-3-901509-84-1, ISSN 1726-9687, Vienna, Austria Breido, J (2013) The State and Prospects of Development of the Interconnected Multi-Motor Semiconductor Electric Drives, Chapter 08 in DAAAM International Scientific Book 2013, pp. 193-212, B. Katalinic \& Z. Tekic (Eds.), Published by DAAAM International, ISBN 978-3-901509-94-0, ISSN 1726-9687, Vienna, Austria Garmash V. et al. (2005) Vozmozhnosti, zadachi i perspektivy volokonnoopticheskikh izmeritel'nykh sistem v sovremennom priborostroenii. [Opportunities, Challenges and Prospects of Fiber Optical Measuring Systems in the Instrument] Foton-ekspress, no 6(46), pp. 128-140

Gudkov Y. \& Tuv A. (2013) Perspektivy ispol'zovaniya aktivnykh infrakrasnykh datchikov $\mathrm{v}$ instrumental'nykh sredstvakh kontrolya zashchishchennykh zon. [Prospects of Active Infrared Sensors in Monitoring Tools of Protected Areas]. Quality. Innovation. Education, no 4(95), pp. 48-51

Murashkina T. \& Volchikhin V. (1999) Amplitudnye volokonno-opticheskie datchiki avtonomnykh sistem upravleniya. [Amplitude Fiber-optic Sensors for Control Systems]. Penza:Izdatel'stvo Penzenskogo Gosudarstvennogo Universiteta

Okosi T. et al. (1991). Volokonno-opticheskie datchiki. [Fiber-optic Sensors]. Moscow: Energoatomizdat. ISBN: 5-283-02466-0

Vaclavek, P. \& Blaha, P. (2007). Ac Induction Machine Speed Estimation using Electrical Quantities Harmonic Analysis, Chapter 22 in DAAAM International Scientific Book 2007, B. Katalinic (Ed.), Published by DAAAM International, ISBN 3-901509-60-7, ISSN 1726-9687, Vienna, Austria

Zak E. (1989)Volokonno-opticheskie preobrazovateli s vneshney modulyatsiey [Fiber-optic Transducers with External Modulation]. Moscow: Energoatomizdat. ISBN: 5-283-01502-6 